\title{
A Study on Parental Involvement and Academic Achievement in Elementary School Students
}

Ng Wee Kuan, Tan Wee Chuen*

Faculty of Education and Social Sciences, Raffles University Iskandar, 80000 Johor Bahru, Johor, Malaysia

*Corresponding author: tanweechuen@raffles-university.edu.my

\begin{abstract}
Previous findings indicated that greater parental involvement will lead to better educational outcomes (Hoover-Dempsey \& Sandler, 1997). This research aims to examine the relationship between parental involvement and student's academic achievement. A quantitative survey design was employed in the study. The samples were 150 families/parents of primary 3 students in a primary school at Johor Bahru. Pearson's $r$ correlation was used to examine the relationship between parental involvement and student's academic achievement. However, contrary to previous findings, the results showed that there was no significant relationship between parental involvement and student's academic achievement $(\mathrm{n}=110 ; \mathrm{r}=0.175 ; \mathrm{p}>0.05)$. In spite of the inconsistency, we found there is a significant relationship between the construct of parental self-efficacy and student's academic achievement.
\end{abstract}

Keywords: Parental involvement, academic achievement, primary education, parental self-efficacy

(C) 2017 Penerbit UTM Press. All rights reserved

\subsection{INTRODUCTION}

Parents are playing crucial role in their children's lives and growth (Al-Matalka, 2014). They have the capability to inculcate the values that are important and meaningful to them. A philosopher, John Locke (1690) proposed that children born as a blank slate, called "tabula rasa". It implied that children do not carry any information and knowledge when they are born and all knowledge is acquired through environmental experiences. Jeynes (2005) revealed that there was a significant relationship between parental involvement and academic achievement among urban elementary students. The reason was because these two variables can generate educationally oriented learning environment. It enables parents to understand their children to a certain degree and provide support during their studies.

Additionally, Velleymalay (2012a) has paralleled this study and suggested that there is a positive relationship between parental involvement and student's academic achievement in Perak, Malaysia. He further explained that not only the socioeconomic status (SES) of parents influenced the level of involvement, but the cooperation of school (eg. expressing appreciation for parents' support) played a major role in increasing the amount of involvement.

Many elementary schools in Malaysia identified student's academic intellectual level with their academic achievement at school (Ministry of Education, 2015). As a matter of fact, it was interesting to understand whether the involvements of parents in their children's educations have a strong impact on their academic achievement. This study aims to examine the relationship between parental involvement and academic achievement. Quantitative research design was conducted to answer the research question: Is there any significant relationship between parental involvement and academic achievement in primary school students?

\subsection{THEORETICAL FOUNDATION OF THE STUDY}

When children are born, parents usually act as the primary educators of them (OECD, 2012). Therefore, parenting behaviors and attitudes will directly influence their children's learning outcomes. Parents who value the importance of learning, provide children emotional support and adequate amount of cognitive stimulation during early education enable children to achieve positive learning outcomes (OECD, 2012). Moreover, International Child Development Initiatives (ICDI, 2012) stated that positive parenting behaviors and attitudes are largely determined by parent's socioeconomic status, including parent's social class, education level, and psychosocial health. In addition, parent's cognitive development during their childhood has a powerful effect on their children's cognitive abilities as well.

Children learn and develop themselves from many ways, for example parents, teachers, and community (ICDI, 2012). Children are not only learned through formal education, the importance of parental participation in their studies should not be neglected. Bronfenbrenner (1986) proposed the bio-ecological model which stated that a child's development is shaped by the experiences from his or her immediate environments (eg. schools) and even broader biological, social, and cultural contexts. From this point of view, children learning process should not be limited to school, but also needed to include family, peers, and society. These components also play a critical role in determining children's educational outcomes. 
In addition, Epstein (2001) proposed a model called "overlapping spheres of influence" which stated that the interaction between family, school, and community have a direct impact on student's learning outcomes. These three parties have to cooperate together to develop supportive relationship to support children's learning. Children are able to learn more and succeed in school if they (eg. children, parents, teachers, and community members) are willing to share their responsibilities. Moreover, children act as a mediator in teachers-parents relation by discussing, for example school activities with their parents and parent's working status with the teachers (Deslandes, 2001).

There are many psychological factors in which determine whether parents will involve in their children's education. Parental role construction is one of the factors that motivate their future involvement in children's education (Hoover-Dempsey and Sandler, 1997). It refers to parents will behave in a way that is consistent with the social roles or expectations. A set of social norms will define how a parent ought to behave. In school context, parental roles are influenced by the family, school, cultural background as well as parent's belief system about children development. These expectations will give pressure to parents when they think about their roles and behaviors in children's education (Hoover-Dempsey and Sandler, 1997). When parents are willing to take their roles, it indicated that they are intrinsically motivated to integrate social expectations about their roles into their self-expectations. This concept is congruent with a theory of motivation- self-determination theory (Deci \& Ryan, 2000).

Self-determination theory maintained that people have the innate tendency to become intrinsically motivated to assimilate themselves into a larger social world (Sansone \& Harackiewicz, 2000). However, to become intrinsically motivated, people need to experience three basic psychological needs, including autonomy, competency, and relatedness. With these three needs, it enables people to enhance their performance with creativity and persist longer. Applying this concept to parents, when parents decide to engage in their children's education, they are more likely to increase their engagement and sustain it for a longer period. On the other hand, if parents become involved in children's education only when receiving invitations from school, they are less likely to be intrinsically motivated. It will subsequently influence their involvement quality (Ghavifekr et al., 2014).

Parental self-efficacy level plays a decisive part in future involvement of children's education. Self-efficacy is the core idea of social cognitive theory which is proposed by Bandura (1993). It refers to how well the person believes that he or she has the abilities to deal with prospective demands and situations. According to this theory, parents develop their sense of efficacy through personal aspirations about their children's performance and then make action plan to achieve the desired outcomes (Bandura, 1993). People with high levels of selfefficacy tend to set higher goals and display high level of competency. They are more willing to put forth effort and persist longer to achieve the desired outcome. Applying this concept to parents, those who have high efficacy tend to engage in their children's schooling because they believe that their contributions will bring advantages to their children's academic achievement (Gutman \& Akerman, 2008). On the other hands, parents with a low sense of efficacy are less likely to involve in their children's education.

Together with parental role construction, it is reasonable to conclude that the higher parental role construction and self-efficacy parents have, the higher the likelihood they become involved in their children's education. That is, parents who believe that they are responsible for their children's schooling and display high level of efficacy are more likely to engage in their children's learning process (Deslandes, 2001).

Parents decide to take part in children's educational process when they perceived invitations for involvement from either their children or the children's teacher (Hoover-Dempsey \& Sandler, 1995). There are two types of invitations, including general and specific invitations. General invitations are involved more in a warm and inviting environment, for example attending school day's events. It represents a sign of welcome when parents visit to school. On the other hand, specific invitations refer to specific demands requested by the children or teachers, for example children ask to solve their homework problems or teachers expect parents to supervise their children homework (Hoover-Dempsey \& Sandler, 1995).

According to Hoover-Dempsey and Sandler (1995), specific invitations from children or teachers are more effective in motivating parental future involvement than general invitations. It is because general invitations do not have enough power to construct parental role. Also, when parents display high level of role construction and self-efficacy, they tend to believe that their involvements are critical for children's academic success (Walker et al., 2005). Therefore, general invitations are not necessary to take the place to influence parent's future involvement.

Walker et al. (2005) further stated that specific invitations presented by children or school teachers will influence parental involvement form. For instance, children who always ask parents to assist their homework will lead parents to become focused on supervising children's homework. Similarly, school teachers who always communicate with parents by using phone and invite questions from parents may facilitate future parent-teacher interactions. Therefore, the types of parental involvement are largely determined by the specific demands of children and teachers.

According to Smith et al. (2007), ongoing and regular communication between the school and parents help to forge a trust relationship between two parties. It is crucial for them to develop partnerships as well as maintain a positive relationship. If parents are convinced that the school teachers always appreciate their efforts and contributions to their children's education, they are more likely to be motivated to participate in school activities actively (Bull, Brooking, \& Campbell 2008). Hence, receiving positive and quality communication from the school teachers will enhance parent's feelings of comfort with the school.

Emerson, Fear, Fox, and Sanders's studies (2012) also stated that building trust relationship between parents and teachers can facilitate the future parental involvement. When there is a mutually trusting and respectful relationship between two parties, it will in turn increase the likelihood for parents to reply the invitations and involve in activities that direct toward children's educational outcomes. It will also increase their perception of the importance of engaging in children's learning (role construction) (Emerson, Fear, Fox, \& Sanders, 2012).

In addition to parental role construction, parental self-efficacy, and parental perceptions of invitation for involvement from child or teacher, parental perceptions of life contexts also play a role in moderating their decisions for future engagement, for example available time and energy as well as knowledge and skills (Hoover-Dempsey \& Sandler, 1995). There are many causes that reduce parent's times and energies to participate in children's studies, for example working status and family size. Gettinger \& Waters (1998) stated that time and energy is the biggest challenges to effective parental involvement.

Furthermore, parental skills and knowledge are also important variables that influence their level and form of engagement (HooverDemsey \& Sandler, 1995). For example, parents who are highly educated tend to believe in their abilities to communicate effectively with the school teachers and provide guidance to their children's academic difficulties. Walker et al. (2005) further suggested that specific skills 
and knowledge in which parents possess will subsequently determine their choices of specific engagement type. For instance, parents who emphasize the importance of English subject will use English language to communicate with their children. Parents will always rely on certain engagement strategy that they feel comfortable and can be successful.

\subsection{CONCEPTUAL FRAMEWORK}

Many research indicated that there was a strong relationship between parental involvement and student's academic achievement that has not been applying to all countries and cultures (Jeynes, 2005; Walker et al., 2005). Other variables may moderate student's academic achievement instead of parental involvement. Nevertheless, in Malaysia, there are limited studies in this area. It is necessary to investigate whether the assumptions from the previous findings can be applied to Malaysia context. Therefore, the study of the relationship between parental involvement and academic achievement in primary school students become important.

Moreover, the study becomes significant when a study identified that approximately $64 \%$ of parents sent their children to private tuition in 2005 (Ubbudari Husaina, 2014). Moreover, there is an increased amount of students are sent to the private tuition every year. The reason is because they hope that their children can pass their exams with flying colors after sending them to the private tuition. They greatly emphasize on the performance of exam which is in line with the Integrated Curriculum for Primary Schools's (ICPS) (or Kurikulum Bersepadu Sekolah Rendah, KBSR, Malay version) exam-oriented approach. Moreover, Ghavifekr et al. (2014) suggested that many parents are high demanding and like to compare their children's performance in school with others. They also tend to exaggerate little or unnecessary things in school. It indicates that parents are not only concerned with their children's learning process, but also concerned with the school environment.

This study aims to examine the relationship between parental involvement and students' academic achievement. Figure 1 illustrated the conceptual model of the study.

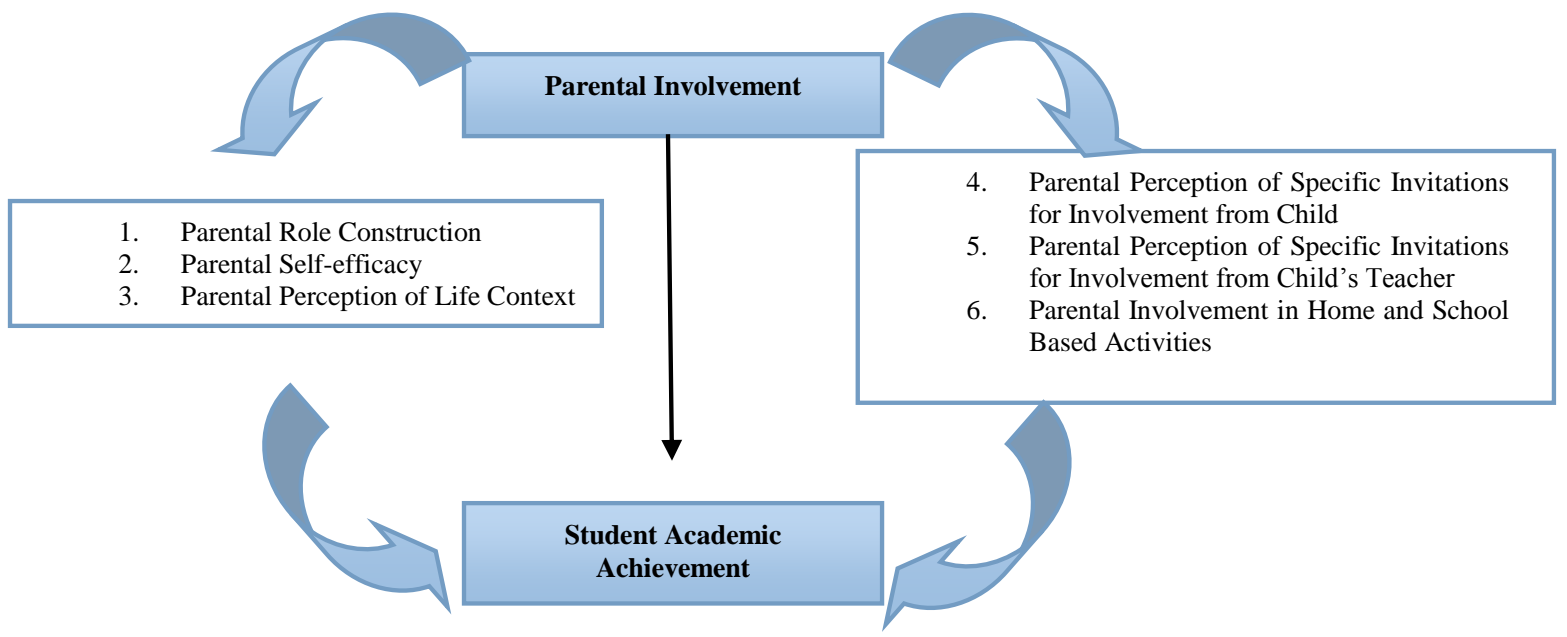

Figure 1 Research conceptual model

In general, parental involvement was defined as the participation of parents in children's learning activities and educational process (Jeynes, 2007). In this research, parental involvement is divided into two main areas, including home and school. At home, there are many prominent aspects, for example discussing school activities, aspirations and expectations, reading, checking homework as well as home rules and supervision (Shute et al., 2011). On the other hand, at school, the important areas are contacting school instructor and volunteering at school (Shute et al., 2011). The study has identified the conceptual model based on the theoretical foundation of this study as discussed in the above section. The model consists of the study of relationship between the parental involvement and academic achievement. Six main components were identified under parental involvement which are:

i. Parental role construction

ii. Parental self-efficacy

iii. Parental perception of life context

iv. Parental Perception of Specific Invitations for Involvement from Child

v. Parental Perception of Specific Invitations for Involvement from Child's Teacher

vi. Parental Involvement in Home and School Based Activities

Academic achievement was defined as using standardized tests (eg. exam) to measure student's knowledge and skills (Ganai and Mir, 2013). The grading and scoring system are used in school to describe the students' performance in order to reflect their learning abilities. 


\subsection{METHODOLOGY}

\section{Research Design}

This study used quantitative research design. A survey design was employed in the current study. The study was conducted in an elementary school in Malaysia.

\section{Research Instrument and Participants}

Two questionnaires were used in the study. Firstly, a demographics questionnaire was administered to collect the data regarding the gender, age, educational status, ethnicity, occupation, and income. The demographics questionnaire was made on the basis of Velleymalay's (2012b) version. Secondly, the questionnaires were adapted from Walker et al. (2005). It consists of a 6-point self-report scale and was used by the researcher to measure parental involvement. The overall reliability statistic of the parental involvement questionnaire achieved a reliability of $0.70-0.84$ (Walker et al., 2005).

The questionnaire consisted of 52 items. Of these, there were 10 items in which measured parental role construction, 7 items measured parental self-efficacy, 6 items for parents' perceptions of specific invitations for involvement from the child, 6 items for parent's perspectives of specific invitations for involvement from the teacher, 13 items measured parental perception of life context and 10 items measured parents' involvement in home- and school-based activities.

A non-probability purposive sampling was used in the research sampling. Participants of this study were the parents of primary 3 students from a primary school. Parents of students from Band A and Band B were selected by the school to participate in the research. It was also the purpose of the school to understand whether band A students (students who achieve good grades in their examination on the previous year) could achieve good results was because of greater parental involvement compared to students in band B(students achieve normal or below normal grades in their examination on the previous year). Half of the participants were the parents of band A students whereas the other half were the parents of band B students. A total of 150 participants (or families) recommended by the school had participated in this study voluntarily. However, the researcher received 110 completed responses. Therefore, a total of 110 responses was used in the data analysis.

Prior to conducting research , 150 sets of questionnaires which included demographic and Walker et al.'s (2005) parental involvement questionnaires was prepared. A translate version of the questionnaire in Chinese was prepared to help the parents to understand the items of the questionnaire. The researcher distributed the questionnaire to student's parent. The questionnaire consists of brief introduction and the consent form. Parents were allowed to withdraw from the study at any time. A week was given to the parent to complete the questionnaire. The class teachers helped to collect responses from the parents. The data were entered into SPSS for further analysis. Pearson's $r$ correlation was used to examine the relationship between parental involvement and student's academic achievement.

\subsection{RESULTS AND DISCUSSION}

\section{Descriptive Data Analysis on Parental Involvement and Student's Academic Achievement}

Table1 represents the means and standard deviations of each parental involvement construct and student's academic achievement. The mean range of the constructs of parental involvement was 1 to 6 while the student's academic achievement was 1 to 100 . It was clear that the highest mean was parental role construction (5.01) whereas the lowest mean was parental perception of specific invitations from child's teacher (2.12). Moreover, the mean score of two constructs were the same (3.07), which included parental perception of specific invitations from child and parental involvement in home and school based activities. Nevertheless, the overall mean of parental involvement was 3.63 .

For standard deviations, it was noticeable that student's academic achievement was the highest (14.72). In the constructs of parental involvement, parental perception of specific invitations from child's teacher showed slightly higher than other constructs which was 1.11 . The overall standard deviation of parental involvement was 0.51 .

Table 1 Means and standard deviations for each parental involvement construct and student's academic achievement

\begin{tabular}{lcc}
\hline \multicolumn{1}{c}{ Construct } & Mean & Standard Deviation \\
\hline Parental Role Construction & 5.01 & 0.50 \\
Parental Self-efficacy & 3.95 & 0.50 \\
Parental Perception of Life Context & 4.56 & 0.58 \\
Parental Perception of Specific Invitations for Involvement from Child & 3.07 & 1.01 \\
Parental Perception of Specific Invitations for Involvement from Child's Teacher & 2.12 & 1.11 \\
Parental Involvement in Home and School Based Activities & 3.07 & 0.95 \\
Overall & 3.63 & 0.51 \\
Student's Academic Achievement & 75.19 & 14.72 \\
\hline
\end{tabular}

\section{Correlational Analysis between Parental Involvement and Student's Academic Achievement}

Table 2 presents the output of correlational analysis between parental involvement and student's academic achievement. It showed that there was a weak but positive correlation between overall parental involvement and student's academic achievement. However, there was no significant relationship between two variables $(n=110 ; r=0.175 ; p>.05)$. 
Table 2 Output of correlational analysis between parental involvement and student's academic achievement

\begin{tabular}{|c|c|c|c|c|c|c|c|c|c|}
\hline \multicolumn{10}{|c|}{ Correlations } \\
\hline & & $\begin{array}{l}\text { STUDENTAC } \\
\text { HIEVEMENT }\end{array}$ & $\begin{array}{l}\text { Parental } \\
\text { Role } \\
\text { Construction }\end{array}$ & $\begin{array}{c}\text { Parental } \\
\text { Perceived } \\
\text { LifeContext }\end{array}$ & $\begin{array}{l}\text { Parental } \\
\text { PerceptionOf } \\
\text { InvitationsFor } \\
\text { Inv olvement } \\
\text { From Child }\end{array}$ & $\begin{array}{l}\text { Parental } \\
\text { PerceptionOf } \\
\text { InvitationsFor } \\
\text { Involvement } \\
\text { FromTeacher }\end{array}$ & $\begin{array}{c}\text { Parental } \\
\text { Involvement } \\
\text { InHomeAnd } \\
\text { School } \\
\text { Based } \\
\text { Activities }\end{array}$ & $\begin{array}{l}\text { ParentalSelf } \\
\text { Efficacy }\end{array}$ & MeansAll \\
\hline \multirow[t]{3}{*}{ STUDENTACHIEVEMENT } & Pearson Correlation & 1 & .159 & .167 & $.224^{*}$ & $-.251^{* *}$ & $.240^{*}$ & $.378^{*}$ & .175 \\
\hline & Sig. (2-tailed) & & .097 & .082 & .019 & .008 & .012 & .000 & .067 \\
\hline & $\mathrm{N}$ & 110 & 110 & 110 & 110 & 110 & 110 & 110 & 110 \\
\hline \multirow[t]{3}{*}{ ParentalRoleConstruction } & Pearson Correlation & .159 & 1 & $.585^{* *}$ & $.217^{*}$ & .059 & $.284^{* *}$ & .122 & $.472^{* *}$ \\
\hline & Sig. (2-tailed) & .097 & & .000 & .023 & .537 & .003 & .202 & .000 \\
\hline & $\mathrm{N}$ & 110 & 110 & 110 & 110 & 110 & 110 & 110 & 110 \\
\hline \multirow{3}{*}{$\begin{array}{l}\text { ParentalPerceiv edLif e } \\
\text { Context }\end{array}$} & Pearson Correlation & .167 & $.585^{* *}$ & 1 & $.267^{\star *}$ & .114 & $.372^{* *}$ & $.358^{* *}$ & $.584^{\star}$ \\
\hline & Sig. (2-tailed) & .082 & .000 & & .005 & .236 & .000 & .000 & .000 \\
\hline & $\mathrm{N}$ & 110 & 110 & 110 & 110 & 110 & 110 & 110 & 110 \\
\hline \multirow{3}{*}{$\begin{array}{l}\text { ParentalPerceptionOf } \\
\text { InvitationsFor } \\
\text { InvolvementFromChild }\end{array}$} & Pearson Correlation & $.224^{*}$ & $.217^{*}$ & $.267^{* *}$ & 1 & $.438^{* *}$ & $.720^{* *}$ & .126 & $.812^{*}$ \\
\hline & Sig. (2-tailed) & .019 & .023 & .005 & & .000 & .000 & .191 & .000 \\
\hline & $\mathrm{N}$ & 110 & 110 & 110 & 110 & 110 & 110 & 110 & 110 \\
\hline \multirow{3}{*}{$\begin{array}{l}\text { ParentalPerceptionOf } \\
\text { InvitationsFor } \\
\text { InvolvementFromTeacher }\end{array}$} & Pearson Correlation & $-251^{* *}$ & .059 & .114 & $.438^{*}$ & 1 & $.446^{* *}$ & -.103 & $.656^{*}$ \\
\hline & Sig. (2-tailed) & .008 & .537 & .236 & .000 & & .000 & .283 & .000 \\
\hline & $\mathrm{N}$ & 110 & 110 & 110 & 110 & 110 & 110 & 110 & 110 \\
\hline \multirow{3}{*}{$\begin{array}{l}\text { Parentallnv olv ementln } \\
\text { HomeAndSchoolBased } \\
\text { Activ ities }\end{array}$} & Pearson Correlation & $.240^{*}$ & $.284^{* *}$ & $.372^{* *}$ & $.720^{*}$ & $.446^{* *}$ & 1 & .176 & $.849^{*}$ \\
\hline & Sig. (2-tailed) & .012 & .003 & .000 & .000 & .000 & & .066 & .000 \\
\hline & $\mathrm{N}$ & 110 & 110 & 110 & 110 & 110 & 110 & 110 & 110 \\
\hline \multirow[t]{3}{*}{ ParentalSelf Ef ficacy } & Pearson Correlation & $.378^{* *}$ & .122 & $.358^{* *}$ & .126 & -.103 & .176 & 1 & $.307^{*}$ \\
\hline & Sig. (2-tailed) & .000 & .202 & .000 & .191 & .283 & .066 & & .001 \\
\hline & $\mathrm{N}$ & 110 & 110 & 110 & 110 & 110 & 110 & 110 & 110 \\
\hline \multirow[t]{3}{*}{ MeansAll } & Pearson Correlation & .175 & $.472^{\star *}$ & $.584^{* *}$ & $.812^{*}$ & $.656^{* *}$ & $.849^{\star *}$ & $.307^{* *}$ & 1 \\
\hline & Sig. (2-tailed) & .067 & .000 & .000 & .000 & .000 & .000 & .001 & \\
\hline & $\mathrm{N}$ & 110 & 110 & 110 & 110 & 110 & 110 & 110 & 110 \\
\hline
\end{tabular}

Correlation is significant at the 0.05 level (2-tailed).

For the correlation between the components of parental involvement and student's academic achievement, parental self-efficacy had the strongest correlation with student's academic achievement $(\mathrm{r}=0.378)$ while parental role construction had the weakest correlation with student's academic achievement $(\mathrm{r}=0.159)$. Gutman and Akerman (2008) stated that parents who have high level of efficacy are more likely to engage in children's education because they believe that their contributions are worth and meaningful to children's studies. Hence, the current findings were congruent with previous research. By referring to parent's self-efficacy level, it could predict their level of involvement which in turn influenced student's academic achievement. However, Hoover-Dempsey and Sandler (1997) suggested that the way parents construct their roles will influence their future involvement in children's education. When they perceived that they are important educators in their children's learning process, they are more likely to initiate their involvement in children's education. The current findings did not in line with the previous assumption.

Moreover, there was a negative relationship found between parental perception of specific invitations for involvement from child's teacher and student's achievement $(\mathrm{r}=-0.251)$. Contrary to previous findings, the previous research maintained that parental perception of invitations for involvement from child or teacher play a decisive part in future involvement (Hoover-Dempsey and Sandler, 1995).

Other variables, for example parental perception of life context, parental perception of invitations for involvement from child as well as parental involvement in home and school-based activities reported a weak but positive correlation of $0.167,0.224$, and 0.240 respectively with student's academic achievement. Gettinger and Waters (1998) described that parental perception of life contexts will play a role in influencing their future engagement. Additionally, Hoover-Dempsey and Sandler (1995) stated that parental involvement activities are largely determined by the specific invitations either from child or teacher. Therefore, parental engagement activities are highly related to children's learning needs.

Looking at the correlation between parental involvement variables, parental perception of invitations for involvement from child had had the strongest relationship with the construct of parental involvement in home and school-based activities $(r=0.720)$. Walker et al. (2005) suggested that specific invitations conveyed by child or teacher are critical for determining parental engagement form. It implied that specific invitations from either child or teacher would have a direct impact on parental engagement activities. On the other hand, the weakest correlation was found between parental perception of invitations for involvement from teacher and the parental role construction $(\mathrm{r}=0.59)$. Furthermore, there was only one negative relationship found between parental role construction and parental perception of invitations for involvement from teacher $(\mathrm{r}=-0.103)$.

In addition, some of the parental involvement variables were still considered highly correlated with other constructs by looking at the stars given. For example, there were two asterisks indicated between parental role construction and parental perception of life context $(\mathrm{r}=$ 0.585), parental role construction and parental involvement in home and school-based activities $(\mathrm{r}=0.284)$, parental perception of invitations for involvement form child and parental perception of life context $(\mathrm{r}=0.267)$, parental involvement in home and school-based activities and parental perception of life context $(\mathrm{r}=0.372)$, parental self-efficacy and parental perception of life context $(\mathrm{r}=0.358)$, parental perception of invitations for involvement from child and teacher $(\mathrm{r}=0.438)$, and parental perception of invitations for involvement from teacher and parental involvement in home and school-based activities $(\mathrm{r}=0.446)$. 


\subsection{CONCLUSION}

There were a lot of inconsistencies found in the study, however, the findings illustrated the strong evidence that parental self-efficacy had an impact on student's academic achievement. These findings had implications especially to the parents and the school. It is important for parents to develop a strong sense of confidence of their abilities in assisting children's learning. It would bring advantages to their children's learning outcomes.

School plays a crucial role in collaborating with parents by implementing parental involvement programs. School could offer such programs to encourage parents to share their difficulties and feelings with each other to make them realize that they were not alone. It would in turn facilitate their sense of efficacy and develop a positive and reinforcing relationship between the school and parents. Epstein's (2001) model of overlapping spheres of influence implied that the cooperation between the school and parents will have powerful effects on student's educational outcomes.

Moreover, the current study also reported a strong relationship between parental perception of specific invitations for involvement from child or child's teacher and parental involvement in home and school-based activities. These findings were important to the teachers and students. They had to initiate the actions (eg. children asked for homework help and teachers gave a call to parents) before parental involvement could take the place. However, it did not mean that students and teachers had to take all the responsibility, parents also needed to engage in children's studies actively.

This study examined different components of parental involvement and their relationships with student's academic achievement. Although the results demonstrated that there was no significant relationship between overall parental involvement and student's academic achievement, parental self-efficacy was found related to student's academic achievement

\section{References}

Al-Matalka, F.I.M. (2014). The Influence Of Parental Socioeconomic Status On Their Involvement At Home. International Journal of Humanities and Social Science, 4(5), 146-154

Bandura, A. (1993). Perceived Self-Efficacy In Cognitive Development And Functioning. Educational Psychologist, 28(2), 117-148.

Bronfenbrenner, U. (1986). Ecology of The Family As A Context For Human Development: Research Perspectives. Developmental Psychology, $22,723-742$.

Bull, A., Brooking, K. \& Campbell, R. (2008). Successful Home-School Partnerships. Report prepared for Ministry of Education by New Zealand Council for Educational Research.

Deci, E.L. \& Ryan, R.M. (2000). Intrinsic and Extrinsic Motivations: Classic Definitions And New Directions. Contemporary Educational Psychology, 25, 54-67

Deslandes, R. (2001). A Vision of Home-School Partnership: Three Complementary Conceptual Frameworks. Paper Prepared for the European Research Network about Parents in Education conference, Rotterdam, The Netherlands.

Emerson, L., Fear. J., Fox, S., and Sanders, E. (2012). Parental Engagement In Learning And Schooling: Lessons From Research. A Report by the Australian Research Alliance for Children and Youth (ARACY) for the Family-School and Community Partnerships Bureau: Canberra.

Epstein, J. L. (2001). School, Family, And Community Partnerships: Preparing Educators And Improving Schools. Boulder, CO: Westview Press.

Ganai, M.Y. \& Mir, M.A. (2013).A comparative Study Of Adjustment And Academic Achievement Of College Students. Journal of Educational Research and Essays, 1(1), 5-8.

Gettinger, M., \& Waters, K. W. (1998). Parental Involvement In Schools: Parent And Teacher Perceptions Of Roles, Efficacy, And Opportunities. Journal of Research and Development in Education, 32, 38-52.

Ghavifekr, S., Lim, A.S.H., Hee, F.L., \& Tan, M.C. (2014). Heads of Departments As Transformational Leaders In Schools: Issues And Challenges. Malaysian Online Journal of Educational Management (MOJEM), 2(3), 119-139.

Gutman, L. \& Akerman, R. (2008). Determinants of Aspirations. University of London, Institute of Education

Hoover-Dempsey, K.V. \& Sandler, H.M. (1995). Parental Involvement In Children's Education: Why Does It Make A Difference? Teachers College Record, 97(2), 311-331.

Hoover-Dempsey, K.V., \& Sandler, H. M. (1997). Why do Parents Become Involved In Their Children's Education? Review of Educational Research, 67(1), 3-42

International Child Development Initiatives (ICDI, 2012). Parental Involvement in early learning. Retrieved from http://www.bernardvanleer.org/files/Parental_involvement_in_early_learning.pdf

Jeynes, W.H. (2005). A Meta-Analysis Of The Relation Of Parental Involvement To Urban Elementary School Student Academic Achievement. Urban Education, 40, 237-269.

Ministry of Education (MOE) (2015). Retrieved from http://apps2.moe.gov.my/kurikulum/v2/

OECD (2012). Let's Read Them A Story! The Parent Factor In Education, PISA, OECD Publishing. Retrieving from http://dx.doi.org/10.1787/9789264176232-en

Sansone, C. \& Harackiewicz, J.M. (2000). Intrinsic and Extrinsic Motivation: The Search For Optimal Motivation And Performance. San Diego, CA: Academic Press.

Shute, V.J., Hansen, E.G., Underwood, J.S., and Razzouk, R. (2011). A Review Of The Relationship Between Parental Involvement And Secondary School Students' Academic Achievement. Education Research International, 2011, 1-10

Smith, F., Driessen, G., Sluiter, R. \& Sleegers, P. (2007). Types Of Parents And School Strategies Aimed At The Creation Of Effective Partnerships. International Journal about Parents in Education, 1(0), 45-52.

Ubbudari Husaina, M. (2014). The Effect Of School Based Assessment (SBA) On Private Tutoring: A Pilot Study. 1-15.

Velleymalay, S.K.N. (2012a). Bridging School And Parents: Parental Involvement In Their Child's Education. Journal of Studies in Education, 2 (1), $41-57$.

Velleymalay, S.K.N. (2012b). The Impact Of Parent's Socioeconomic Status On Parental Involvement At Home: A Case Study On High Achievement Indian Students Of A Tamil School In Malaysia. International Journal of Academic Research in Business and Social Sciences, 2(8), 11-24.

Walker, J.M.T., Wilkins, A.S., Dallaire, J.R., Sandler, H.M., \& Hoover-Dempsey, K.V. (2005). Parental Involvement: Model Revision Through Scale Development. The Elementary School Journal, 106(2), 85-104. 